\title{
Morphology of the lingual papillae in the Asian golden cat
}

\author{
By \\ Shoichi EMURA \\ Heisei College of Health Sciences, Gifu-shi, Gifu 501-1131, Japan \\ -Received for Publication, February 8, $2018-$
}

\begin{abstract}
Key Words: Asian golden cat, lingual papillae, scanning electron microscopy
Summary: We microscopically examined the dorsal lingual surface of an adult Asian golden cat (Catopuma temminckii). The papillae on the margin of the lingual apex were horny-shaped and fungiform. The filiform papillae on the anterior part of the lingual body were large and cylindrical; the connective tissue core of each of these comprised a large conical papilla. The filiform papillae on the central part of the lingual body were large and conical-shaped on the medial side and dome-shaped on the lateral side. The connective tissue core of each medial filiform papilla comprised a large main process and some secondary processes, while processes were absent on the lateral side. These findings are peculiar to the tongue of members of the family Felidae.
\end{abstract}

Many studies have reported on the structures of the lingual surfaces of various animals. Scanning electron microscopy (SEM) studies have been conducted on the tongues of the cat (Boshell et al., 1982), dog (Iwasaki and Sakata, 1985), mongoose (Iwasaki et al., 1987), Japanese weasel (Furubayashi et al., 1989), sea otter (Shimoda et al., 1996), bush dog (Emura et al., 2000), panther and Asian black bear (Emura et al., 2001), lion (Emura et al., 2003), tiger (Emura et al., 2004), jaguar (Emura et al., 2013), fishing cat (Emura et al., 2014), and black-backed jackal (Emura et al., 2014) belonging to the order Carnivora. Such studies have revealed variations in the morphology and distribution of papillae on the dorsal lingual surface among these species.

However, an SEM analysis of the tongue of the Asian golden cat has not been carried out thus far. Therefore, the purpose of this study was to examine three-dimensionally the dorsal lingual surface and the connective tissue core of the Asian golden cat, and compare the results with those of previous reports on other mammals.

\section{Materials and Methods}

The tongue of one adult Asian golden cat of the family Felidae was used in this study. The tongue was fixed in $10 \%$ formalin. Small blocks containing papillae were cut with a razor blade and post-fixed with $1 \%$ osmium tetroxide for $1 \mathrm{~h}$. Thereafter, the specimens were dehydrated through a graded series of acetone exchange fluids and critical-point-dried. To examine the three-dimensional connective tissue structure of the lamina propria of the mucosa, some of the samples were washed in distilled water after fixation and macerated in $3.5 \mathrm{~N} \mathrm{HCl}$ at $35^{\circ} \mathrm{C}$ for $3 \mathrm{~d}$. After maceration, the tissues were washed in distilled water, post-fixed in $1 \%$ osmium tetroxide for $1 \mathrm{~h}$, and dehydrated in a series of acetone exchange fluids and critical-point-dried. All specimens were sputtered with Pt-Pd before examination by SEM (Hitachi S-3500N, Tokyo, Japan) at an accelerating voltage of $10 \mathrm{kV}$.

\section{Results}

Macroscopically, the tongue of the Asian golden cat was about $11 \mathrm{~cm}$ long. Filiform papillae are distributed over the entire dorsal surface of the lingual body (Fig. 1). There were no foliate papillae. Vallate papillae were located on both sides of the posterior end of the lingual body (Fig. 1).

SEM analysis revealed that the papillae on the margin of the lingual apex were horny-shaped and fungiform (Fig. 2a). The connective tissue cores of these hornyshaped papillae resembled talons in shape, while those of 


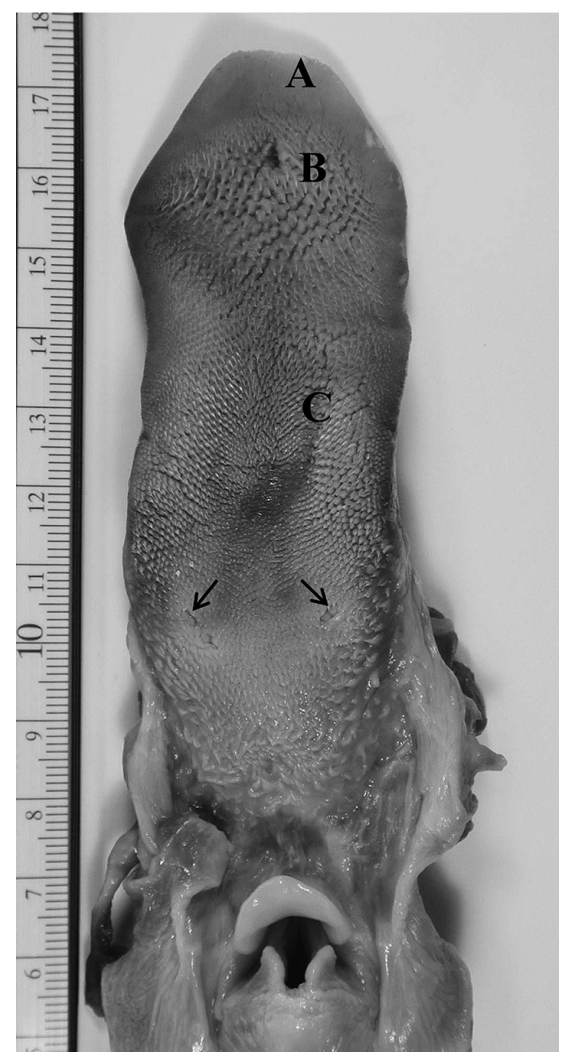

Fig. 1. Macrograph of Asian golden cat tongue. A, B, C, and arrows show the parts prepared for scanning electron microscopy (SEM).
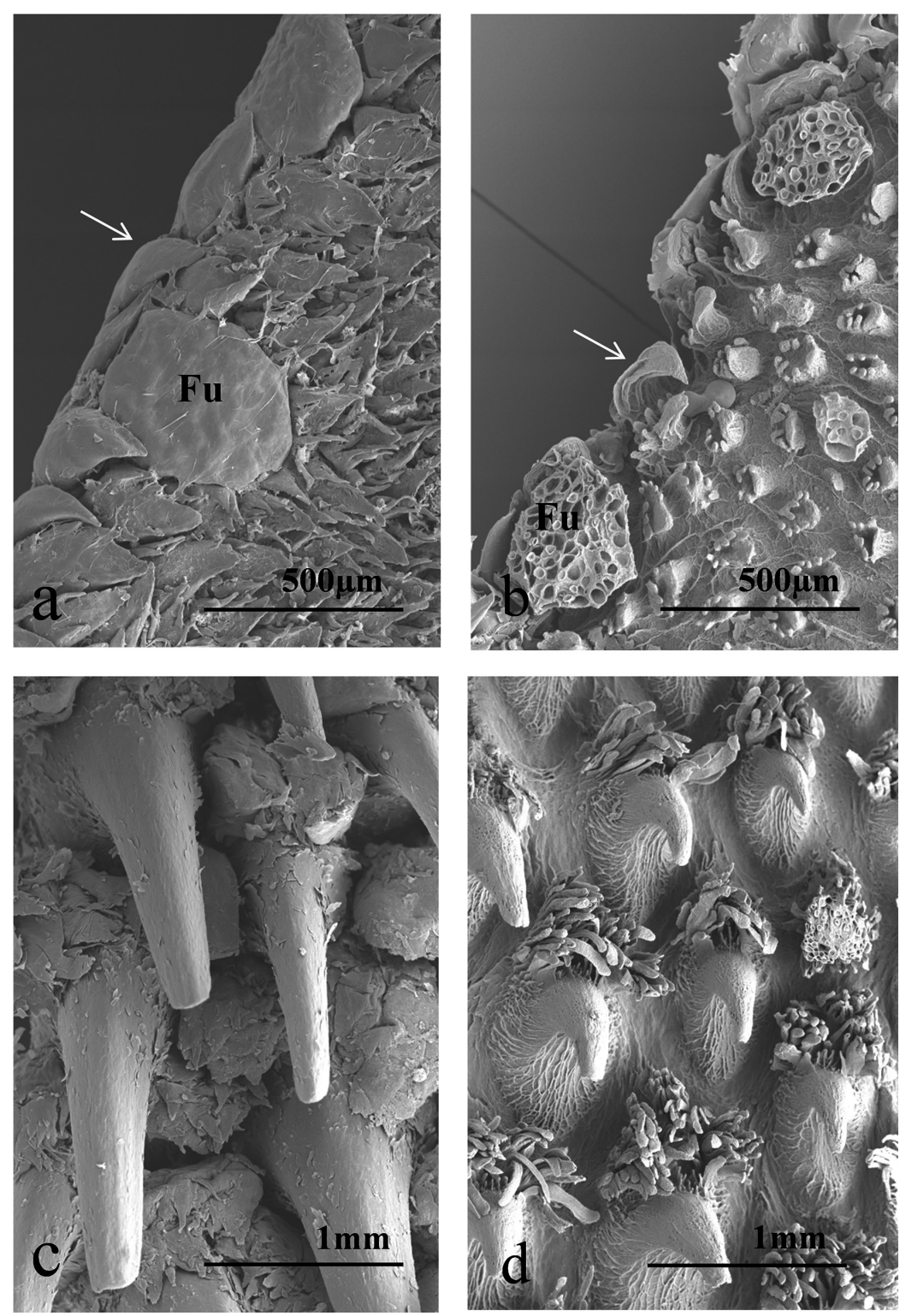

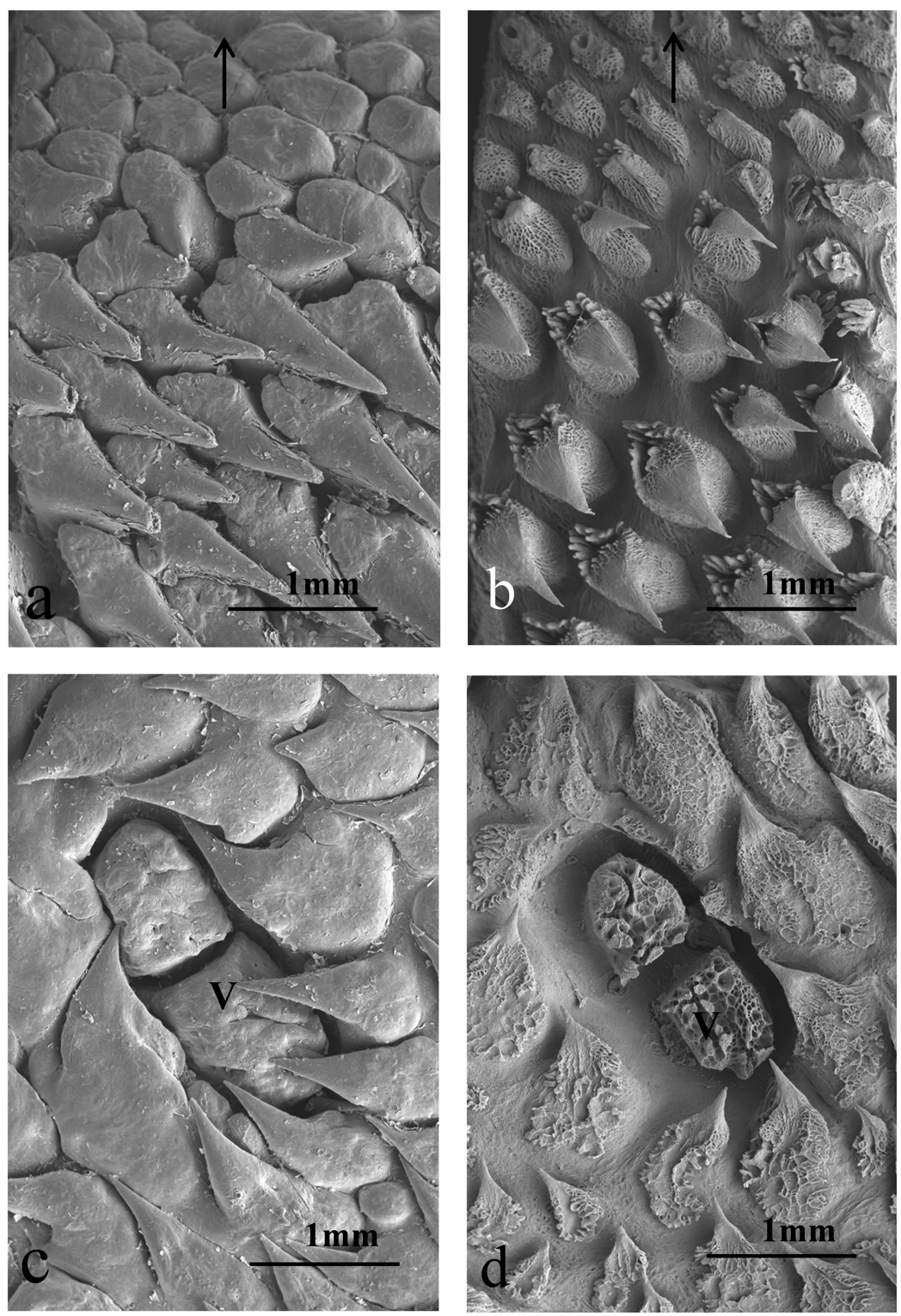

Fig. 3. (a, b) SEM micrographs of C in Fig. 1. The filiform papillae on the central part of the lingual body are large and conical-shaped on the medial side and dome-shaped on the lateral side. The connective tissue core of each of the medial filiform papillae consists of a large main process and some secondary processes, while those of the lateral side do not have processes. (c, d) SEM micrographs of arrows in Fig. 1. The vallate papilla $(\mathrm{V})$ is surrounded by a groove. The top of the connective tissue core of the vallate papilla has many ditches. Arrow represents the lateral direction of the tongue.

\section{Discussion}

Shimoda et al. (1996) reported that the filiform papillae on the margin of the tongue of a newborn sea otter are divided into two shapes: horned and club-shaped, and the fungiform papillae are divided into hemispherical and club-shaped. Emura et al. $(2001,2003)$ reported that large papillae were observed on the margins of the lingual apexes of a newborn panther, a newborn Asian black bear, and a newborn lion. In the cat (Boshell et al., 1982), newborn panther (Emura et al., 2001), lion (Emura et al., 2003), tiger (Emura et al., 2004), jaguar (Emura et al., 2013), and fishing cat (Emura et al., 2014), a marked transition occurs between the tip and mid-portion of the dorsum of the tongue. This transition is characterized by an increase in size of the projections of the filiform papillae. In the midportion of the tongue, these projections are very prominent. This finding is fairly consistent with our observations of the tongue of the Asian golden cat. Furthermore, the marked regional variation in size and 
morphology of the filiform papillae in the Asian golden cat tongue contrasts with descriptions of tongues in planteating animals. The filiform papilla on the lingual apex consists of a large main papilla and some secondary papillae in the fishing cat (Emura et al., 2014). The connective tissue core of the filiform papilla on the lingual body consists of a large conical papilla or a large main process and some secondary processes in the jaguar and fishing cat (Emura et al., 2013, 2014). Their structures are similar to those of the Asian golden cat. These reports show that the Asian golden cat tongue has a peculiarity of the tongue of the family Felidae.

Many studies have described the three-dimensional structure of the vallate papillae in the mammalian tongue. In particular, several studies have shown that the vallate papillae are flattened and oval in shape and are surrounded by a groove and a pad (Krause and Cutts, 1982; Chamorro et al., 1986; Qayyum et al., 1988; Chunhabundit et al., 1992; Agungpriyono et al., 1995; Atoji et al., 1998; Emura et al., 2013). The vallate papillae of the cat, dog, and flying squirrel have been found to be encircled by filiform papillae in the posterior body (Boshell et al., 1982; Iwasaki and Sakata, 1985; Emura et al., 1999). Equine vallate papillae are composed of a primary papilla that is divided into several secondary papillae by intermediate grooves (Chamorro et al., 1986). Occasionally, in bovine vallate papillae, twin papillae are surrounded only by a primary papillary groove (Chamorro et al., 1986). The vallate papillae of the bush dog are surrounded by a groove and a crescent pad, and on the dorsal surfaces of these papillae, small conical papillae have been observed (Emura et al., 2000). In addition, some vallate papillae of the Asian black bear have been shown to be composed of primary papillae that are divided into several secondary papillae by intermediate grooves (Emura et al., 2001). This vallate papilla was also observed in the Asian golden cat in this study.

In conclusion, the morphological characteristics of the tongue in the Asian golden cat were found to be similar to those of other members of the family Felidae.

\section{Acknowledgements}

I am grateful to the staff of Tennoji Zoo for supplying the specimen.

\section{References}

1) Atoji Y, Yamamoto Y, Suzuki Y: Morphology of the tongue of a male Formosan serow (Capricornis crispus swinhoei). Anat Histol Embryol 1998; 27:17-19.

2) Agungpriyono S, Yamada J, Kitamura N, Nisa C, Sigit K, Yamamoto Y: Morphology of the dorsal lingual papillae in the lesser mouse deer, Tragulus javanicus. J Anat 1995; 187:635-640.

3) Boshell JL, Wilborn WH, Singh BB: Filiform papillae of cat tongue. Acta Anat 1982; 114:97-105.

4) Chamorro CA, de Paz P, Snadval J, Fernandez JG: Comparative scanning electron-microscopic study of the lingual papillae in two species of domestic mammals (Equus caballus and Bos Taurus). I. Gustatory papillae. Acta Anat 1986; 125:83-87.

5) Chunhabundit P, Thongpila S, Somana R: SEM study on the dorsal lingual surface of the common tree shrew, Tupaia glis. Acta Anat 1992; 143:253-257.

6) Emura S, Hayakawa D, Chen H, Shoumura S: Morphology of the dorsal lingual papillae in the newborn panther and Asian black bear. Okajimas Folia Anat Jpn 2001; 78:173-178.

7) Emura S, Hayakawa D, Chen H, Shoumura S: SEM and gross study on the lingual surface of the lion, Panthera leo (in Japanese). Mammalian Science 2003; 43:45-50.

8) Emura S, Hayakawa D, Chen H, Shoumura S: Morphology of the lingual papillae in the tiger. Okajimas Folia Anat Jpn 2004; 81: $39-44$.

9) Emura S, Okumura T, Chen H: Morphology of the lingual papillae in the jaguar. Okajimas Folia Anat Jpn 2013; 89:93-97.

10) Emura $S$, Okumura $T$, Chen $H$ : Morphology of the lingual papillae in the fishing cat. Okajimas Folia Anat Jpn 2014; 90:79-83.

11) Emura S, Tamada A, Hayakawa D, Chen H, Jamali M, Taguchi H, Shoumura S: SEM study on the dorsal lingual surface of the flying squirrel, Petaurista leucogenys. Ann Anat 1999; 181:495-498.

12) Emura S, Tamada A, Hayakawa D, Chen H, Shoumura S: Morphology of the dorsal lingual papillae in the bush dog (Speothos venaticus). Okajimas Folia Anat Jpn 2000; 77:137-142.

13) Furubayashi R, Sato E, Ishibashi T: Histological pattern of the tongue in the Japanese weasels, Mustera itatsi, with special reference to the morphology and distribution of papillae, taste buds and lingual glands (in Japanese). Acta Anat Nippon 1989; 64:210-214.

14) Iwasaki S, Miyata K, Kobayashi K: Comparative studies of the dorsal surface of the tongue in three mammalian species by scanning electron microscopy. Acta Anat 1987; 128:140-146.

15) Iwasaki S, Sakata K: Scanning electron microscopy of the lingual dorsal surface of the beagle dog. Okajimas Folia Anat Jpn 1985; 62:1-14.

16) Krause WJ, Cutts JH: Morphological observations on the papillae of the opossum tongue. Acta Anat 1982; 113:159-168.

17) Shimoda $T$, Nakanishi E, Yoshino S, Kobayashi S: Light and scanning electron microscopic study on the lingual papillae in the newborn sea otter Enhydra lutris. Okajimas Folia Anat Jpn 1996; 73:65-74.

18) Qayyum MA, Fatani JA, Mohajir AM: Scanning electron microscopic study of the lingual papillae of the one humped camel, Camelus dromedaries. J Anat 1988; 160:21-26. 